Proceedings of the Institution of
Civil Engineers
Municipal Engineer 156
June 2003 Issue ME2
Pages $127-133$
Paper 13012
Received $26 / 07 / 2002$
Accepted $06 / 05 / 2003$
Keywords:
developing countries/education \&
planning/infrastructure planning/
social impact
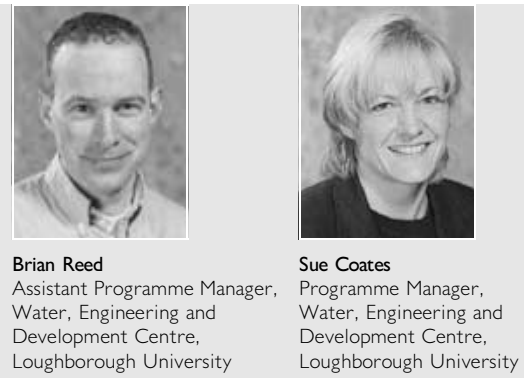

\title{
Engineering and gender issues-evidence from low-income countries
}

\section{B. J. Reed and S. Coates}

Engineers' work has an impact on society, economically, environmentally and socially. However, society is not uniform and some people will benefit or be adversely impacted more than others. Access to decision making is one important factor in determining the impact on different social groups. In low-income countries, the development of infrastructure can transform the domestic chores of collecting water, fuel or food and can improve the local environment through improved sanitation. Many of these tasks are the responsibility of women, yet they can be excluded from the development process. Engineers can contribute to the inclusion of socially excluded groups of people through increasing the involvement of men and women in engineering decision making and adopting technologies that suit women's needs, resulting in better infrastructure and more equitable societies.

\section{INTRODUCTION}

This paper sets outs some of the reasons why the needs of men and women should be considered in developing infrastructure in low-income countries. It reports on a research project looking at the role of the engineer and how using engineering skills and perspectives can contribute to the practical and social needs of men and women.

One billion people in the world lack access to safe water supply and $2 \cdot 4$ billion lack adequate sanitation. ${ }^{1}$ International development targets aim to reduce the proportion of people who lack access to these essential services by half by 2015 . While $96 \%$ of the population of Europe have adequate water services, about $40 \%$ of Africans and 20\% of people in Asia and Latin America and the Caribbean are unserved. Lack of water is related to poverty and '70 per cent of the World's poor are female' (a controversial and rough figure from the UNDP Human Development Report ${ }^{2}$ ).

Engineers working in development (government employees, private operators or non-governmental organisations) have to provide sustainable solutions. This does not only require that the product they provide is appropriate, but that the design and construction process meets the users' needs (Fig. 1).

\section{I.I. Putting policies into practice}

Increasingly, policies call for social issues to be included in the civil engineering process in low-income countries. The profession will need to change if it is to respond to these policies and help meet the international development targets. A recurrent issue is the need for gender awareness. These polices should be translated into contracts, construction and concrete action, but discontinuities within the project cycle and lack of practical guidance may result in policies not being implemented. Where policies do make their way into engineering contracts, engineers who can show an understanding of the concepts and the

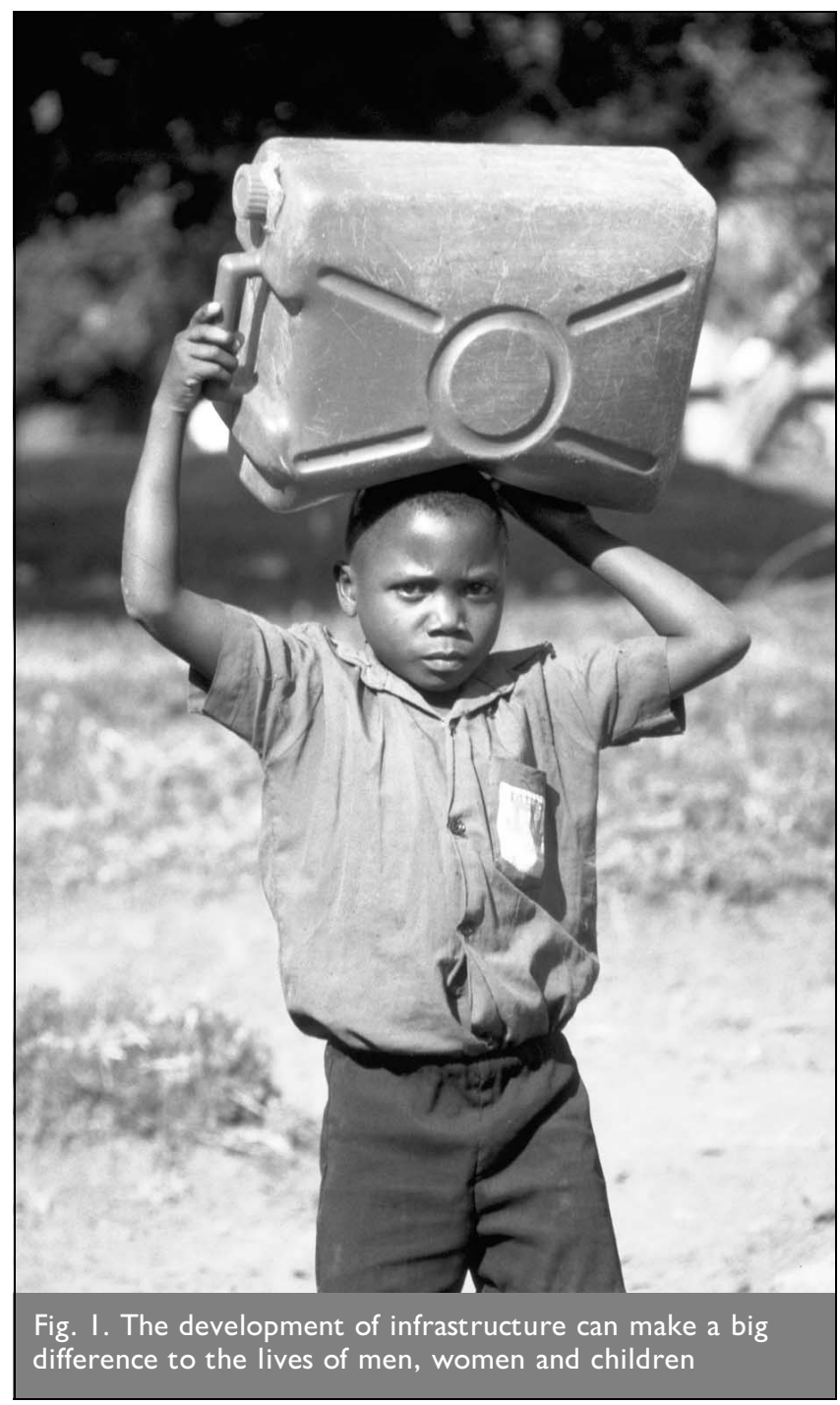


contribution they can make are in a more advantageous position than engineers who treat social issues as being outside the scope of engineering.

Supported by a UK Department for International Development (DFID) Knowledge and Research project, staff at the Water, Engineering and Development Centre (WEDC), Loughborough University, with collaborators in the UK, India, Nigeria, Zambia and South Africa, have been looking at how engineers can contribute to gender policies and practice. This has included the collection of case studies and a series of workshops with practitioners in Africa, India and the UK.

\section{I.2. What is gender?}

In development engineering, gender issues are seen as an integral part of the development process, ${ }^{3}$ although engineers rarely have any formal instruction in the topic. Gender is concerned with the way society acts towards men and women, as opposed to the physical differences. The term sex refers to tangible differences, such as the fact that women menstruate and men do not, while gender refers to the way men and women behave, such as regarding a menstruating woman as unclean in some cultures. Gender differences can vary between cultures, classes and over time.

Just as with some engineering terminology (such as stress or rock), the definition of gender is often used loosely, with gender being used when women (or more rarely men) should be used. Gender is only one of many ways that society can be analysed, as power relations between people of different economic groups, ages, races, religions, class, caste, physical ability or sexualities can demonstrate how a community operates. An unequal power relation within a society leads to some people having a greater role in decision making and others being socially excluded, leaving them poorer, vulnerable or exploited. Where decisions about infrastructure are made, lack of a voice can mean users end up with a system they cannot or will not use.

\section{I.3. What is the relationship with engineering?}

Thomas Tredgold's (1788-1829) often quoted definition of civil engineering as 'the art of directing the great sources of power in Nature for the use and convenience of man' normally elicits discussion about the first section of the phrase. The goal of being for the use and convenience of society (to use more gender-neutral language) receives less attention in the education and training of civil engineers than the technical aspects of the profession.

Society is not uniform and different sectors of society use infrastructure in different ways. The pedestrian, cyclist, car driver and lorry driver all use roads, but in different ways and they are given different priorities during the design process. Across most societies, but particularly those in low-income countries, it is women who are normally responsible for domestic work (food production and preparation, cleaning, caring for children and the sick) while men carry out more commercial activities, such as paid employment. Thus innovations that have an influence on household tasks, such as a washing machine or a water supply connected to the household, will impact more directly on the lives of women than will innovations, such as long-distance travel, that have an

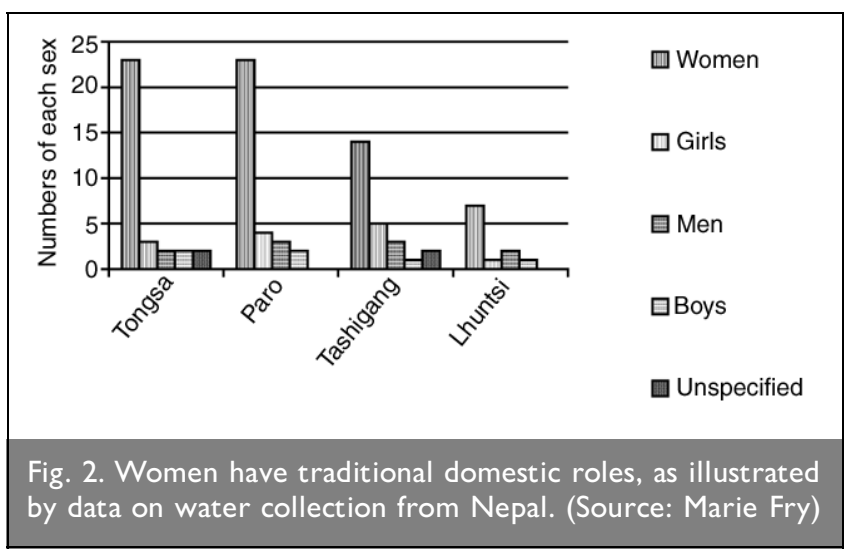

influence on the (male) commercial world. In low-income countries, domestic activities include collecting water for cooking, washing and subsistence farming, collecting fuel for cooking, disposing of solid waste and buying and selling in the local market. Commercial activities include formal agriculture, power generation and transport. See Fig. 2.

In low-income countries, given the inequalities in society, campaigners have proposed a rights-based approach to sustainable development, to provide women equitable access to public services.

In no region do women and men have equal social, economic, and legal rights. In a number of countries women still lack independent rights to own land, manage property, conduct business, or even travel without their husband's consent ... Gender disparities in rights constrain the sets of choices available to women in many aspects of life-often profoundly limiting their ability to participate in or benefit from development. ${ }^{4}$

At a global level and in many countries this has led through the political process to the formation of policies to ensure that women are included in the decision-making process.

Central to [DFID's] work with governments will be to ensure that poor people's interests, and particularly those of women and children, are reflected in national and regional legal and regulatory frameworks. ${ }^{5}$

Separate development projects for women (taking a welfare approach) termed Women in Development (WID) maintained the social differences between men and women. A more balanced Gender and Development approach (GAD) is being advocated, to address the long-term positions of men and women in society.

Taking an engineering viewpoint, however, leads to more pragmatic reasons for considering the needs of women. If a water supply is going to be largely used for domestic purposes, it makes sense to ensure that the people most likely to use it are able to use it fully without any physical, economic or social constraints. Narayan ${ }^{6}$ looked at 121 rural water supply projects and concluded that there was a strong correlation between overall project effectiveness and the participation in the project by the beneficiaries. Thus, water supply projects have been known to fall short of their maximum potential impact due to the failure to involve the main users. Selecting the location, quality, quantity and technical method of water supply are 
fundamental engineering parameters for design, yet the users of the final product are not often consulted. Each of these parameters can determine if the system is going to be usable, in a sustained manner by the target group of users.

\section{DEVELOPING THE GUIDELINES FOR ENGINEERS}

\section{I. Reviewing the literature}

This work focused on domestic water supply and environmental sanitation (the safe disposal of excreta, solid waste and wastewater), as this is one area where women's roles have been clearly recognised. There is well-documented literature on women and water, ${ }^{7}$ mostly by social scientists. Engineering literature recognises the issues but gives little practical advice. ${ }^{8}$ Some mainstream engineering books do not even acknowledge the concern. ${ }^{9,10}$ The main concerns centre on hearing women's voices, either through direct, participative, consultation exercises or through representation on local water and sanitation management boards. The current trend is to move away from women-centred development projects and to advocate that gender issues be integrated into all development projects. However, the standard practice is still to employ gender experts, ${ }^{11}$ a process that can leave gender issues sidelined. ${ }^{12}$ This leaves a discontinuity between engineering actions and gender actions, particularly where professionals do not interact, resulting in a void between listening to women's voices and ensuring that their demands are converted into technical solutions. See Fig. 3.

Engineering practice does not necessarily take into account women's social and physical needs, while gender experts do not know what engineering solutions are available

... very few gender experts have experience or training in management and organizational development in the traditional sense ... This means [gender experts] may not have tools to address the problem which will necessarily be understood or accepted by those who are part of the problem. ${ }^{13}$

An important aspect of the literature review was the collation of some 130 diverse case studies. These were to be used both for analysis and for demonstrating good and poor practice.

\subsection{Gathering evidence}

Two of the proposed research outputs were guidelines for engineers working in low-income country contexts and a set of training notes designed for engineers as well as trainers of engineers. Drafts of both outputs were prepared, based on the literature review and tested with the project partners. The training material was used in South Africa with CSIR and the Mvula Trust and the guidelines were used in a workshop in India with UNICEF. Two clear messages were received from these activities.

(a) Engineers had been specifically invited to the training exercise in South Africa, but the majority of participants were social scientists and other non-engineers, sent as deputies for the engineers.

(b) Engineers did attend the workshop ${ }^{14}$ in India but felt that the guidelines did not address the issues they encountered. They were aware of the importance of involving women in the development of water supplies, and employed local

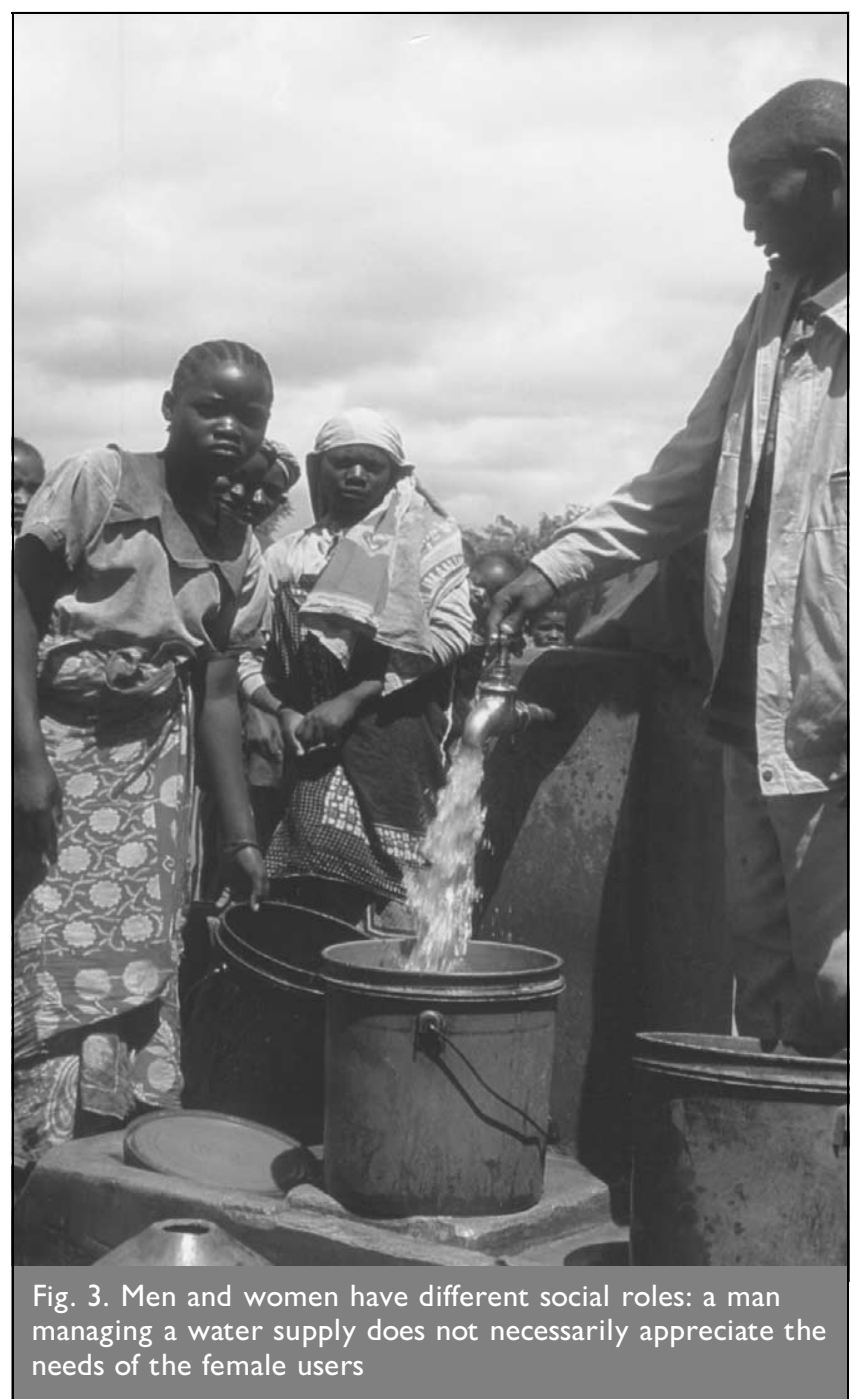

women to act as caretakers for supply systems. However, technical questions remained, including how do you design an elevated water tank that a woman can climb up to in a sari, complete her task, remain safe and respectable? (See Fig. 4.)

The results of these two exercises showed that the guidelines needed to address the design dilemmas faced by engineers and

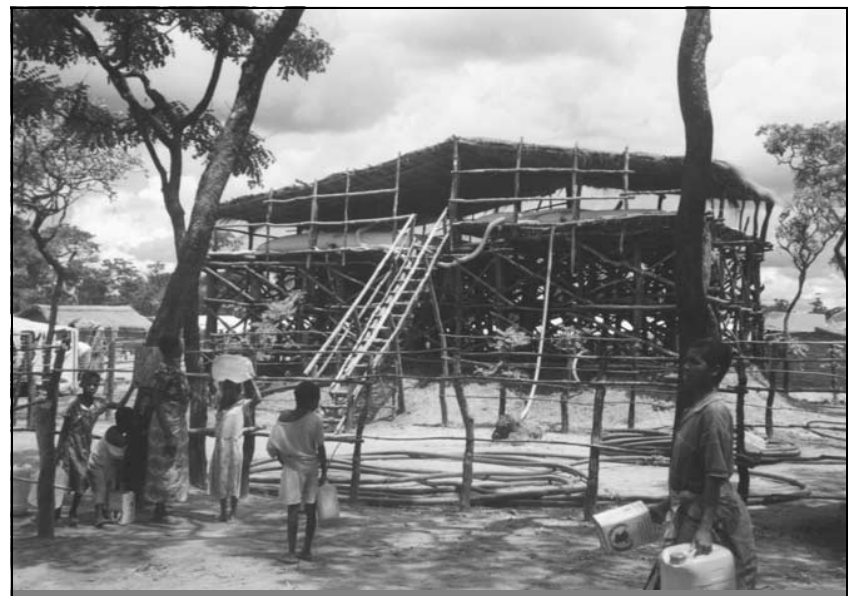

Fig. 4. The choice between steps or a ladder to reach water tanks is a technical issue, but women in long clothes may not be able or willing to climb a ladder 
also engage with them, so that gender was seen as an engineering issue and not as a separate activity. The practical knowledge of how to change and adapt standard designs was a critical aspect of challenging accepted practice.

The research team used semi-structured interviews with an international group of technical staff working in emergency relief to explore their perceptions of 'gender'. There was a very low level of understanding of the word 'gender'-its primary purpose seemed to be in funding documents and proposals. There was, however, a high recognition that women's issues were important, although how they could be addressed was not clear. There was also a very low level of knowledge about the physical and sanitary needs of women, such as issues surrounding menstruation, pregnancy and childcare. The safety of women from harassment was also seen to be a low priority in terms of design criteria. Traditional gender roles were apparent in both the refugees' activities (women being responsible for domestic activities such as food preparation, childcare, looking after the sick and collecting water, men having paid work) and the jobs of the emergency workers themselves (fewer women being involved in technical activities).

Four other workshops and training sessions were held, with project managers and engineers, to develop the training material. Rights-based reasons for concentrating on gender were less well received than the more pragmatic reasons of project efficiency and effectiveness. The simplistic nature of the social analysis solely along gender lines was also disputed, for example the scenario of well-educated women being given preferential treatment over poorer men and women. ${ }^{15}$ The overt emphasis on gender issues led to lack of engagement by the participants or even hostility (usually, but not always, by men in the group). The participants could identify more closely with diversity issues with many dimensions (poverty, race, age or disability), rather than just equating social exclusion with gender. Where engineers were aware of gender issues, they did not necessarily relate these to their technical work, continuing to use standard designs for latrines, rather than adapting them to users' requirements.

During the research, many of the existing participative tools for raising gender awareness were 'translated' into plainer English, removing social science terminology. However, once the group accepted that gender was a useful, if not entirely problem-free indicator of exclusion from decision making, the question remained, 'What is the engineering response?'

Many of the participative methods used by development professionals to consult with local men and women have been prepared and practised by social scientists. Eliciting mainly social or economic information, the focus is on agreeing mechanisms for community-based operation and maintenance of water supplies and cost recovery rather than seeking men and women's input about technical design and options. Some methods have been developed to select a level of service which different sectors of society would like to see (such as willingness to pay, sanitation ladders ${ }^{16}$ or 'participation, ranking, experience, perceptions and partnership' (PREPP) ${ }^{17}$ ). However, discussing engineering information or setting technical priorities does not feature highly in the range of participative tools nor has attention been paid to introducing engineers to the methods as a technical design tool.

\section{RESULTS}

Following the workshops, the guidelines and training material were redrafted, so they addressed the engineering context more closely. This included the material and the style of delivery of the guidelines, ${ }^{18}$ for example the inclusion of engineering drawings rather than more idealised pictures of community activities. The training material ${ }^{19}$ was centred on engineering priorities, such as design specifications, rather than external social concerns. To raise awareness of gender among technical personnel, a short booklet ${ }^{20}$ was produced, to encourage uptake of the both the guidelines and the training material.

\section{I. Practical actions for engineers}

Looking at standard civil engineering procedure ${ }^{21}$ and the project cycle enabled the team to consider how engineers can contribute to social inclusion and enhance the effectiveness and efficiency of an infrastructure project. Engineers' main contribution is to ensure that the infrastructure being designed and built is suitable for men and women and meets the users' priorities, rather than carrying out more conventional gender activities, in economic, political, social and cultural life, such as education, empowerment or political representation.

Decisions affecting the usefulness of infrastructure to all segments of society occur through the whole project cycle, starting with policy decisions, such as the choice of projects, and continue until the service is built and is being operated, as different approaches to cost recovery demonstrate. The range of small practical technical choices that can make a difference include designing tap stands that cater for local water containers or latrine squat plates that are easy to clean and prevent snakes entering the pit. Buying cement in $25 \mathrm{~kg}$ bags rather than $50 \mathrm{~kg}$ sacks and providing a range of tool sizes (for example spades or hammers) can enable a wider range of people to work on a construction project (Figs 5 and 6).

Before the level of detailed design, however, terms of reference, contracts, employment policies and specifications need to be inclusive. In training sessions, engineers could readily identify the design specifications that would relate to different sectors of the community, but normally used 'standard' designs that did not provide for all users' needs. Although there is a lack of advice on designing infrastructure for the needs of poor women, engineers' ingenuity can address this. The barrier is ensuring engineers know who they are designing for and what the user wants. Even engineers who are aware of the importance of water and sanitation in women's lives have to make the connection between the technical design and 'gender'.

\subsection{Listening and learning}

A key activity in community-managed projects is enabling people to participate in decision making. It is only through asking people what they need that their demands can be evaluated. Consultation techniques designed to develop awareness of social inequalities or map the economic status of local people do not necessarily help in establishing engineering priorities. However, the underlying principles of promoting discussion and allowing voices to be heard can still be applied. Although many engineering decisions will be context-specific, 


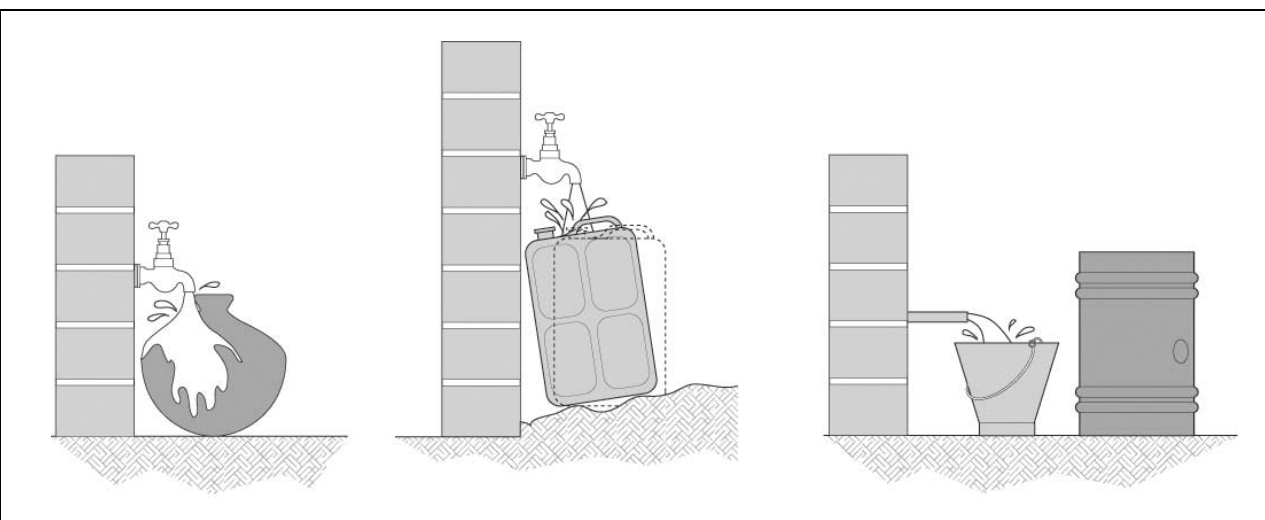

Fig. 5. Technology can meet the needs of men and women-engineers can design water points that address local requirements

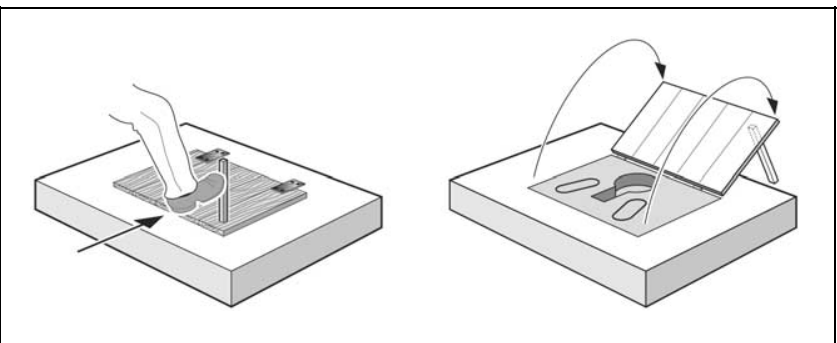

Fig. 6. Design specifications should be developed with the community. If snakes or flies are a perceived issue, then the engineer should address this in the design. This diagram shows a pit latrine with foot-operated cover

the research developed several short exercises to bring design issues to life. For example, an exercise to establish the height of a well wall provides an opportunity for the engineer to discuss other technical issues, such as problems with spilt water or contamination of containers. See Fig. 7.

\subsection{Including the excluded}

The general move from a welfare or 'women in development' approach to a 'gender and development' approach within development has resulted in a shift from practical actions to improve the lives of women to actions that address women's position in society (strategic actions). This has led to a

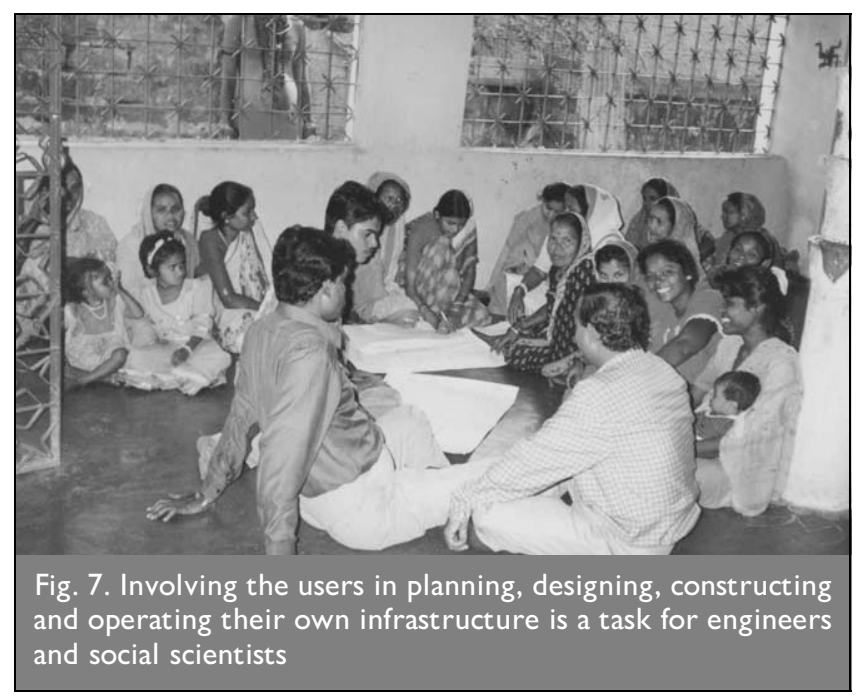

reduction in emphasis on the practical issues that engineers can address through their products.

Engineering project timescales are measured in months or years, rather than the decades real social change can take. Besides the ethical debate over whether social engineering is acceptable, the short period that an engineer is on a project does make it more difficult to address strategic issues. However, engineers can contribute to the reduction of social exclusion, or, more importantly, can ensure that the socially excluded are not further disadvantaged by the action of engineers. The engineering product (what is produced) may address practical issues (such as delivering water) but the engineering process (how it is produced) can include the excluded (by employing people from all sectors of society and asking representatives of each sector their opinion). Ensuring the participation of all segments of society raises the status of the vulnerable, both in their own eyes and in the eyes of others. Employing women in construction, where appropriate, brings social and economic benefits to them and their families, as well as the practical insight that the users can provide, such as locating raw materials or enabling them to maintain and repair the facility in the future. Indeed, without attention to these social aspects (such as women's status in society), some of the practical actions (such as employing women pump mechanics) may not be possible. See Fig. 8 .

\subsection{The engineers' organisation}

Engineers are not only responsible for projects, they also manage their own organisations. The project looked at the engineering organisation ${ }^{22}$ and introduced both practical and longer-term actions that can make engineering organisations more inclusive and welcoming to a socially diverse workforce. This goes beyond equal opportunities policies to practical aspects of social (especially domestic) roles regarding men and women in the workplace. Working on site or going on field visits may be more difficult for members of staff with commitments outside the office; issues of personal safety and respectability may be more important to female than male staff, but raising awareness of the problem is the first step to finding a solution.

\subsection{Professional development}

Producing a book of guidelines and papers on the subject can only influence a small number of the target audience. In order to help project managers introduce social exclusion issues to their staff in a manner that is tailored to engineers' interests and work patterns, the project developed a set of training notes, ${ }^{23}$ to lead discussion and introduce the fact that women's issues are also engineering issues. The development of these notes was based on a series of workshops with engineers and other technical staff in order to start from their perspective and address their concerns, rather than imposing an external viewpoint. 


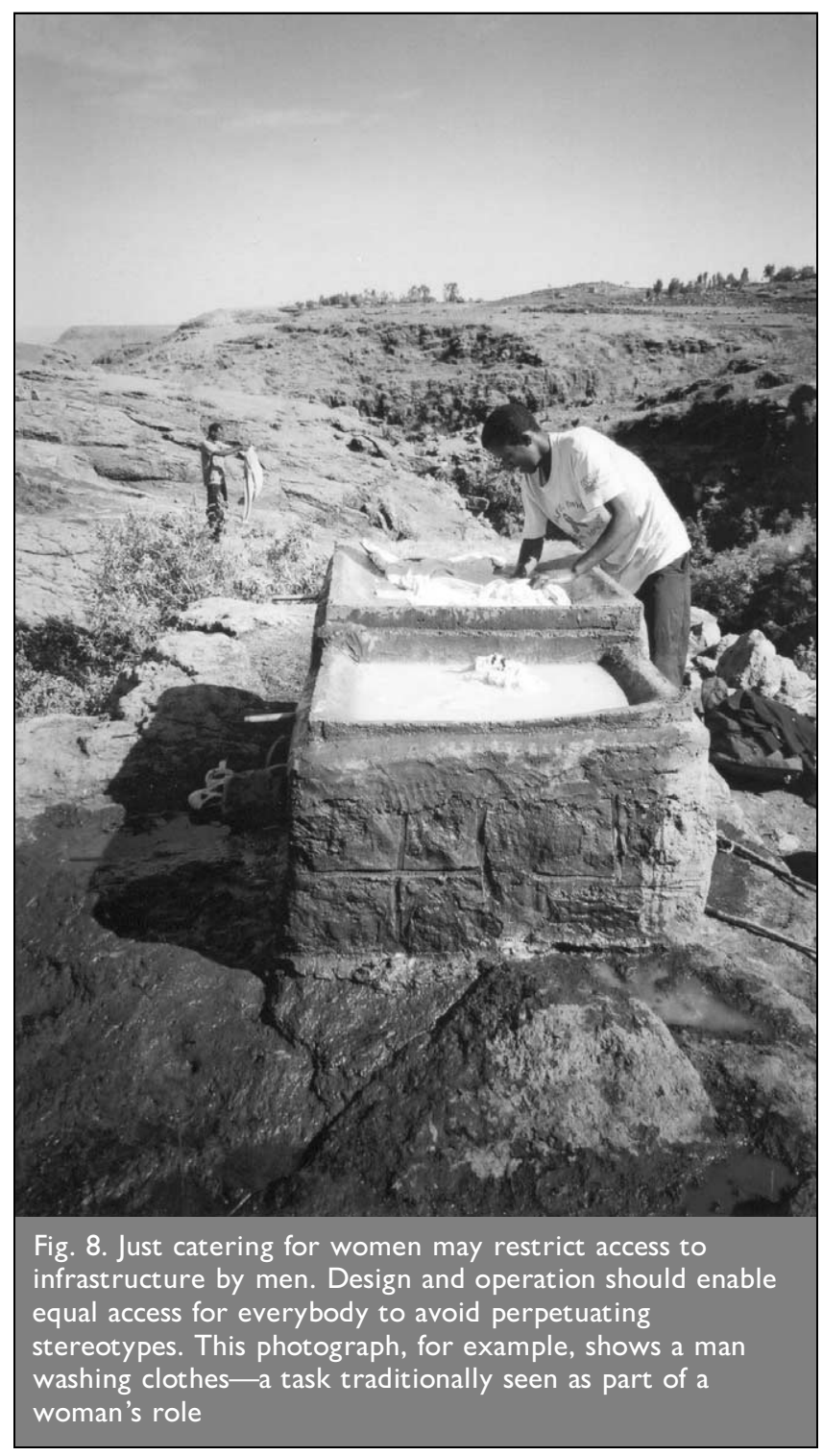

\subsection{Further work}

The research project has managed to fill some gaps in making infrastructure development work more accessible to the most vulnerable members of society. However, it has also exposed some further areas for engineers to develop. The relative scarcity of methods used to engage users in technical decision making is apparent when compared to the wealth of participative techniques for discussion of social and economic information and perceptions.

The fact that this project was needed demonstrates that there is something that needs to be addressed in the education and training of engineers; this does not imply that engineers should become social scientists, but they should have a greater awareness of who they are working for and why. Simplistic concepts of the 'client' need to go beyond meeting the minimum criteria laid down in a terms of reference, design brief or contract specification. Engineers need to understand and accept why a promoter is developing infrastructure, in order to maximise the potential impact of the development and tailor the product to the users' needs, through enabling the users to become involved in the engineering processes of planning, design and construction. This will require engineers to work closely with other disciplines and to understand what

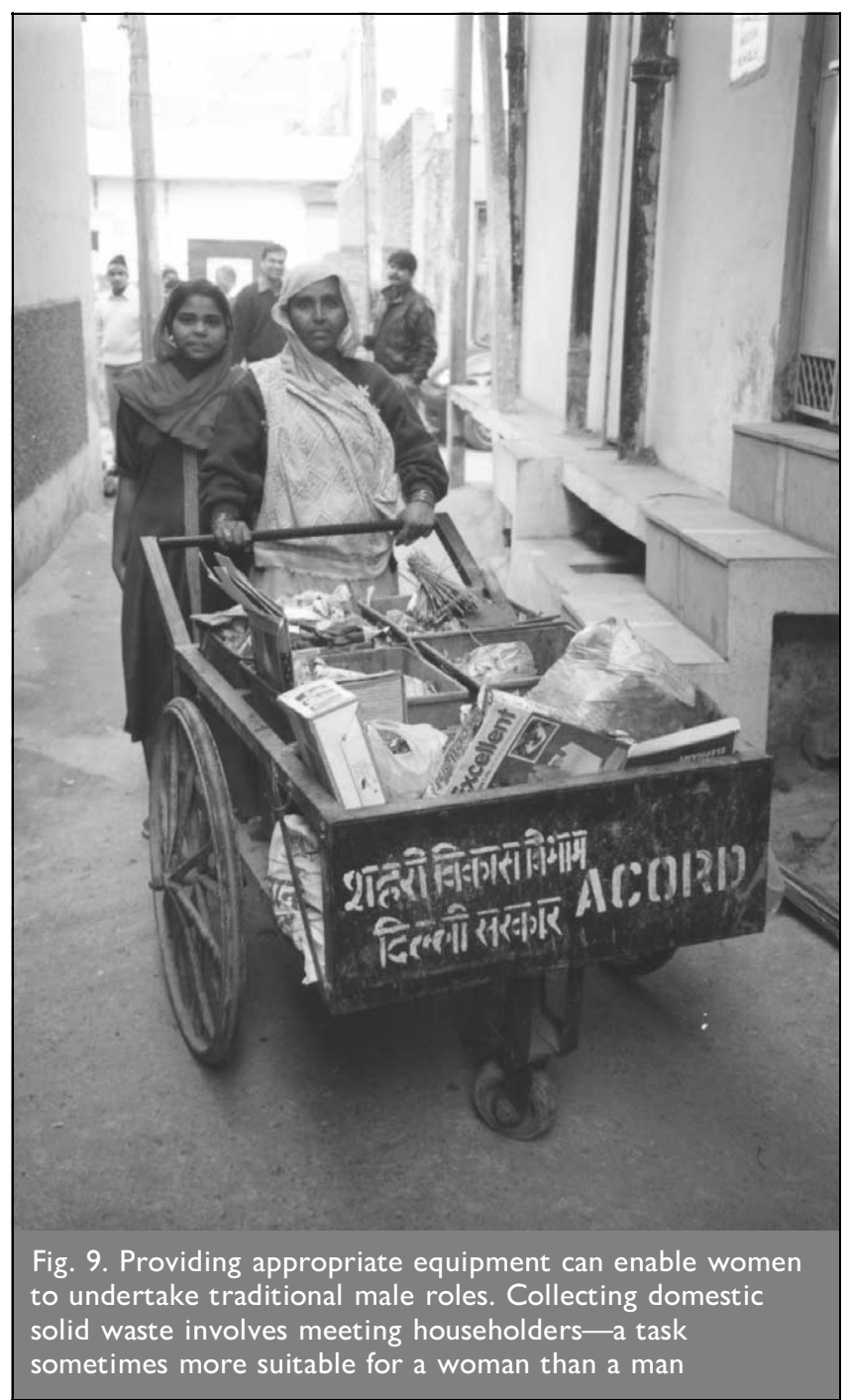

allied professionals can offer. Conversely, social scientists do need to be aware of the range of skills engineers can provide. Some gender experts presently recommend that the number of women on a committee indicates the consideration of women's priorities in the implementation of infrastructure. Engineers need to demonstrate that technical aspects are also important in ensuring that the development of infrastructure contributes positively to the lives of vulnerable people. See Fig. 9.

\section{CONCLUSIONS}

This article cannot relate all the detailed information elicited over several years of research but some recurrent issues are apparent. The involvement of local men and women in the development of the infrastructure that they will be using makes the technical aspects of a project more effective. However, standard project practices need to alter to accommodate the involvement of local people, in terms of budgets, programme, personnel, reporting and decision making. Governments in particular will have to operate outside normal conventions to facilitate rather than implement reform. This will need to be supported by developing sources of information and support to which engineers can relate, and instilling a culture of continual professional development so they can take up new developments. The International Development Targets to reduce world poverty will require the physical services that engineers can build, but infrastructure will only contribute to these targets if 
they address the needs of poor people. The current attitudes, skills and knowledge of engineers in addressing the priorities of men and women are not progressing at a fast enough rate to meet these targets.

The conventions of responding to gender issues will also have to be reassessed, to accept that the contributions that engineers can provide can improve the position of excluded members of society, both practically and in the longer term.

\section{ACKNOWLEDGEMENTS}

This research has involved a wide range of partners, but special acknowledgement must be made of the contributions of DFID, Marie Fry, Sarah House, Sarah Parry-Jones, Archana Patkar, Brian Skinner, Mike Smith, Ian Smout, UNICEF India, CSIR South Africa, Mvula Trust South Africa, Médecins Sans Frontières and WaterAid. The views expressed are not necessarily those of these individuals or organisations. Illustrations are all from the project team or WEDC staff.

\section{REFERENCES}

1. Department for International DeVelopment. Addressing the Water Crisis-Healthier and More Productive Lives for Poor People. DFID, London 2001.

2. United Nations Development Programme. Human development report. UNDP, Oxford University Press, New York, 1995.

3. Proceeding of International Conference on Water and the Environment: Development Issues for the 21st Century, Dublin, 1992.

4. WORLD BANK. Engendering Development: Through Gender Equality in Rights, Resources, and Voice. Oxford University Press, 2001.

5. Department For International DeVelopment. Addressing the Water Crisis; Healthier and More Productive Lives for People. DFID, London, 2001.

6. NARAYAN D. The Contribution of People's Participation. World Bank, 1995.

7. VAN WIJK C. et al. IRC International Water and Sanitation Centre, the Netherlands.
8. PICKFORD J. Low Cost Sanitation. WEDC, Loughborough, 1995.

9. TwORT, RATNAYAKA and BRANDT. Water Supply. Arnold/IWA Publishing, 2000, 5th edn.

10. TсHOBANoglous and BuRTon. Wastewater Engineering. McGraw-Hill, 1991, 3rd edn.

11. Gender Checklist: Water Supply and Sanitation. Asian Development Bank.

12. Greene-Roesel J. and Hinton R. Gender, Participation and Institutional Organization in Bhutanese Refugee Camps. In The Myth of Community (GuIJT I. and SнAн M. K. (eds)) Intermediate Technology Publications, 1998.

13. Macdonald M, Sprenger E. and Dubel I. Gender and Organizational Change: Bridging the Gap Between Policy and Practice. Royal Tropical Institute, the Netherlands, 1997.

14. Coates S. and PatKar. A Consultation report. Available at: http://www.lboro.ac.uk/wedc/projects/msgender/index.htm

15. JoshI D and FAWCETT B. Water projects and women's empowerment. Proceedings of the 27th WEDC Conference, Zambia, 2001.

16. Deverill P., Bibby S., Wedgwood A. and Smout I. Designing Water Supply and Sanitation Projects to Meet Demand. WEDC, Loughborough, 2002.

17. Coates S., Sansom K. and Kayaga S. PREPP-improving utility watsan services to low income customers. Proceedings of the 27th WEDC Conference, Zambia, 2001.

18. REED B. J. (ed.). Infrastructure for All. WEDC, Loughborough (forthcoming).

19. ReED B. J. (ed.). Developing Engineers and Technicians. WEDC, Loughborough (forthcoming).

20. REED B. J. (ed.). Building with the Community. WEDC, Loughborough (forthcoming).

21. Institution of Civil Engineers. Civil Engineering Procedure. Thomas Telford, London, 1996.

22. Wearne S. Principles of Engineering Management. Thomas Telford, London, 1993, 2nd edn.

23. Available on the internet at: http://www.lboro.ac.uk/wedc/ projects/msgender/index.htm

Please email, fax or post your discussion contributions to the secretary by I December 2003: email: kathleen.hollow@ice.org.uk; fax: +44 (0)20 7799 1325; or post to Kathleen Hollow, Journals Department, Institution of Civil Engineers, I-7 Great George Street, London SWIP 3AA. 